\title{
A Network Meta-Analysis Comparing Semaglutide Once-Weekly with Other GLP-1 Receptor Agonists in Japanese Patients with Type 2 Diabetes
}

\author{
Neil Webb • Michelle Orme · Michal Witkowski $\cdot$ Rie Nakanishi • \\ Jakob Langer
}

Received: January 19, 2018 / Published online: March 24, 2018

(C) The Author(s) 2018

\section{ABSTRACT}

Introduction: Semaglutide once-weekly (QW) is a novel glucagon-like peptide-1 (GLP-1) analogue administered at a 0.5 or $1.0 \mathrm{mg}$ dose. In the absence of head-to-head trials between semaglutide QW and other GLP-1 receptor agonists (GLP-1 RAs) in a Japanese population, a network meta-analysis (NMA) was performed. The objective was to assess the relative efficacy and safety of semaglutide QW vs GLP-1 RAs in Japanese patients with type 2 diabetes (T2DM), with a specific focus on the comparison between semaglutide $0.5 \mathrm{mg} \mathrm{QW}$ and dulaglutide $0.75 \mathrm{mg}$ QW.

Methods: A systematic review (SR) and supplementary Japanese searches were conducted to identify trials of GLP-1 RAs in Japanese patients

Enhanced content To view enhanced content for this article go to https://doi.org/10.6084/m9.figshare.59195 14.

Electronic supplementary material The online version of this article (https://doi.org/10.1007/s13300018-0397-1) contains supplementary material, which is available to authorized users.

N. Webb · M. Witkowski

DRG Abacus, Bicester, Oxfordshire, UK

M. Orme

ICERA Consulting Ltd., Swindon, UK

R. Nakanishi $\cdot$ J. Langer $(\bowtie)$

Novo Nordisk Pharma Ltd., Tokyo, Japan

e-mail: jklg@novonordisk.com on diet and exercise, who have previously received $0-1$ oral antidiabetic drugs (OADs). Data at 52-56 weeks were extracted for the following outcomes (feasible for analysis in an NMA): glycated hemoglobin $\left(\mathrm{HbA}_{1 \mathrm{c}}\right)$, fasting plasma glucose (FPG), weight, systolic blood pressure (SBP), and overall hypoglycemia. The data were synthesized using an NMA and a Bayesian framework.

Results: Four trials, identified from the SR and Japanese-specific searches, were relevant for inclusion in the NMA. When compared to dulaglutide $0.75 \mathrm{mg}$ QW, semaglutide $0.5 \mathrm{mg}$ QW was shown to provide significant reductions in $\mathrm{HbA}_{1 \mathrm{c}}$ [- $\left.-0.61 \% \quad(12.3 \mathrm{mmol} / \mathrm{mol})\right]$, weight $(-1.45 \mathrm{~kg})$, SBP $(-5.03 \mathrm{mmHg})$, and FPG (- $1.26 \mathrm{mmol} / \mathrm{L})$. No significant differences in the proportion of patients achieving a $\mathrm{HbA}_{1 \mathrm{c}}$ level $<7 \%(53 \mathrm{mmol} / \mathrm{mol})$ or the risk of overall hypoglycemia were observed between semaglutide $0.5 \mathrm{mg}$ QW and dulaglutide $0.75 \mathrm{mg} \mathrm{QW}$.

Conclusion: Overall, semaglutide $0.5 \mathrm{mg}$ QW was associated with significant reductions from baseline in $\mathrm{HbA}_{1 \mathrm{c}}$, weight, SBP, and FPG compared with dulaglutide $0.75 \mathrm{mg}$ QW in Japanese patients with T2DM. These data may provide valuable evidence for clinical decision-making, cost-effectiveness analyses, and health technology appraisal (HTA) requirements.

Funding: Novo Nordisk Pharma Ltd.

Keywords: Dulaglutide; GLP-1 receptor agonist/analogue; Glycemic control; $\mathrm{HbA}_{1 c}$; 
Indirect comparison; Japan/Japanese; Network meta-analysis; Semaglutide; Type 2 diabetes; Weight

\section{INTRODUCTION}

Type 2 diabetes mellitus (T2DM) is characterized by increased insulin insensitivity coupled with a progressive failure of pancreatic $\beta$-cells, resulting in a gradual loss of glycemic control and hyperglycemia [1]. If uncontrolled, hyperglycemia can lead to diabetic complications, including microvascular (e.g., retinopathy) and macrovascular (e.g., myocardial infarction) complications [2]. Globally, the prevalence of diabetes is increasing and it is estimated that 642 million people aged $20-79$ years will have diabetes by 2040; of these people, $87-91 \%$ will have T2DM [3]. In Japan, a national survey has shown that the prevalence of diabetes has increased from 8.9 million in 2007 to 10 million in 2016 [4]. Specifically, a significant increase in the prevalence of T2DM has also been recorded in a cohort study [5]; this study attributed the increase in T2DM to higher rates of obesity and reduced physical activity levels [5].

Treatment for T2DM is focused on the management of hyperglycemia and reducing the levels of glycated hemoglobin $\left(\mathrm{HbA}_{1 \mathrm{c}}\right)$ [6]; the reduction in $\mathrm{HbA}_{1 \mathrm{c}}$ is associated with a reduction in the risk of diabetic complications $[2,7]$. In Japan, the main $\mathrm{HbA}_{1 \mathrm{c}}$ target set by the Japanese Diabetes Society is $<7 \%$ $(53.0 \mathrm{mmol} / \mathrm{mol})$, which was established from the perspective of preventing complications [8]. However, despite the wide range of treatments available, a recent survey has shown that $47 \%$ of patients with T2DM in Japan do not achieve the recommended $\mathrm{HbA}_{1 \mathrm{c}}$ goal [9]. In addition, patients with a higher body mass index (BMI) were less likely to achieve the $\mathrm{HbA}_{1 \mathrm{c}}$ target than patients with a lower BMI [9]. Weight gain is also a known side effect of many oral antidiabetic drugs (OADs) and insulins used to treat T2DM, and may be associated with an increased risk of cardiovascular disease [10, 11].

Glucagon-like peptide-1 receptor agonists (GLP-1 RA) are a class of drugs that act by increasing glucose-dependent insulin secretion, preserving $\beta$-cell function, suppressing glucagon levels, and slowing gastric emptying $[12,13]$. Unlike other therapies in T2DM, treatment with GLP-1 RA is typically associated with weight loss [14-17] and may also reduce cardiovascular risk [18]. In Japan, GLP-1 RAs are increasingly prescribed for the treatment of T2DM and several studies have demonstrated the efficacy and safety of GLP-1 RAs in the Japanese population [19-23]. Studies have also shown that GLP-1 RAs are more effective in Japanese/Asian populations when compared with European populations [24, 25], and are typically administered at a lower dose in the Japanese population [26]. This is because T2DM in Asian patients is primarily characterized by higher $\beta$-cell dysfunction, rather than insulin resistance [27], and GLP-1 RAs have a proven ability to improve $\beta$-cell function [28]. Therefore, GLP-1 RAs are a favorable choice of therapy for this population. Japanese patients with T2DM are also generally less obese than their European counterparts and the exposure of a fixed dose GLP-1 RA will be greater in lighter patients.

Semaglutide once-weekly (QW) is a novel GLP-1 analogue administered at a 0.5 or $1.0 \mathrm{mg}$ dose. The efficacy and safety of semaglutide QW has been assessed across the Semaglutide Unabated Sustainability in Treatment of Type 2 Diabetes (SUSTAIN) clinical trial program, which included two multicenter, head-to-head trials comparing semaglutide QW with exenatide QW or dulaglutide QW. In SUSTAIN 3, treatment with semaglutide QW provided significant reductions in $\mathrm{HbA}_{1 \mathrm{c}}$ and weight when compared with exenatide QW, both as an addon to 1-2 OADs [metformin and/or sulfonylurea (SU) and thiazolidinedione (TZD)] [29]. In SUSTAIN 7, semaglutide QW also provided significant reductions in $\mathrm{HbA}_{1 \mathrm{c}}$ and weight when compared with dulaglutide $\mathrm{QW}$, both as an addon to metformin [30]; however, no Japanese patients were included in this trial.

The efficacy and safety of semaglutide QW in a Japanese population with T2DM were demonstrated in two recent trials. One trial compared semaglutide QW $(0.5$ and $1.0 \mathrm{mg})$ as monotherapy with sitagliptin $100 \mathrm{mg}$ oncedaily (QD) [31]. After 30 weeks, both doses of 
semaglutide QW demonstrated significant reductions in $\mathrm{HbA}_{1 \mathrm{c}}$ and weight compared with sitagliptin $100 \mathrm{mg}$ QD; the safety profile was also comparable to other GLP-1 RAs. Semaglutide QW (0.5 and $1.0 \mathrm{mg}$ ) was also assessed in a 56-week trial of patients who had poor glycemic control on diet and exercise or one OAD [32]. The addition of semaglutide QW was associated with significant improvements in $\mathrm{HbA}_{1 \mathrm{c}}$ and weight when compared with the addition of another OAD.

Following the recent introduction of health technology appraisal (HTA) in Japan and the increasing amount of treatment options available to patients with T2DM, decision-makers need to assess the relative clinical benefits and risks of each treatment to make recommendations on their use within a limited budget. The availability of such comparative clinical data can also be used for cost-effectiveness analyses in Japan in the context of HTA. In the absence of head-to-head trials between semaglutide QW and other GLP-1 RAs in a Japanese population, a network meta-analysis (NMA) was performed. The objective was to assess the relative efficacy and safety of semaglutide QW vs GLP-1 RAs in Japanese patients, with a specific focus on the comparison between semaglutide $0.5 \mathrm{mg}$ QW and dulaglutide $0.75 \mathrm{mg}$ QW; dulaglutide is the latest QW GLP-1 RA in Japan (only available as a $0.75 \mathrm{mg}$ QW dose) and semaglutide $0.5 \mathrm{mg}$ QW is the expected maintenance dose for the Japanese population.

\section{METHODS}

\section{Systematic Review}

A systematic review (SR) was performed in accordance with PRISMA guidelines [33] to identify trials of GLP-1 RAs in Japanese patients with T2DM. Searches of MEDLINE ${ }^{\circledR}$, Embase, and the Cochrane Library were performed via Ovid on April 5, 2016, with updates occurring on October 3, 2016 and August 16, 2017. Searches of conference proceedings were also carried out for the European Association for the Study of Diabetes (EASD; 2014-2016), the International Society for Pharmacoeconomics and
Outcomes Research (ISPOR; 2014-2017), the International Diabetes Federation (IDF; 2013 and 2015), and the American Diabetes Association (ADA) Scientific Sessions (2014-2017). The search results were then screened against the SR eligibility criteria to generate a list of potential studies to include in the NMA (Table S1). As the eligibility criteria of the SR were restricted to studies published in English, a supplementary search of four Japanese language databases (Japan Pharmaceutical Information Center, Japan Science and Technology Information Aggregator, J-GLOBAL, and Igaku Chuo Zasshi) was conducted to ensure all potentially relevant studies had been identified.

Citations of interest were identified by one reviewer and verified by a second independent reviewer on the basis of title and abstract. Full publications were obtained for all citations of interest and were assessed by one reviewer and verified by a second independent reviewer. Any uncertainties were resolved through discussion between reviewers. Data were then extracted into an Excel spreadsheet by one reviewer and checked by a second reviewer. All included references were assessed for risk of bias using a seven-criteria checklist as approved by the National Institute of Health and Care Excellence (NICE) [34].

\section{NMA Methodology}

An NMA was performed to compare the efficacy and safety of GLP-1 RAs in Japanese patients, where the primary intervention of interest was semaglutide $0.5 \mathrm{mg}$ QW and the comparators of interest were all other licensed doses of GLP-1 RAs in Japan-liraglutide QD, dulaglutide QW, exenatide twice-daily (BID), exenatide QW, and lixisenatide QD. In order to reduce variability between populations in different trials, the population of interest was aligned to the two Japanese SUSTAIN trials of semaglutide QW [NN9535-4091 trial (NCT02207374; now available as a full-text publication, Kaku et al. [32]) and NN9535-4092 (NCT02254291; now available as a full-text publication, Seino et al. [31])]. Therefore, while trials investigating a broader population were eligible for inclusion in the SR 
(Table S1), only trials investigating semaglutide QW or other licensed doses of GLP-1 RAs in Japan and in Japanese populations who have previously received 0-1 OADs were considered for further analysis.

The feasibility of performing an NMA at two time points ( 30 and 56 weeks), based on the study durations of the two Japanese SUSTAIN trials, was examined. All trials identified in the SR were examined for data on at least one outcome of interest at approximately 30 weeks (duration of the NN9535-4092 trial [31]) and 56 weeks (duration of the NN9535-4091 trial [32]), and the ability to form a best-case connected network was assessed. The feasibility of generating evidence networks for each of the 20 outcomes of interest (Table S1) was next examined; the outcomes of interest included $\mathrm{HbA}_{1 \mathrm{c}}$ outcomes [e.g., change from baseline, proportion of patients achieving a level $<7 \%$ (53 mmol $/ \mathrm{mol})]$, weight, BMI, systolic blood pressure (SBP), fasting plasma glucose (FPG), postprandial plasma glucose, and safety outcomes (including the incidence of overall hypoglycemia).

The analysis of continuous outcomes (e.g., change from baseline in $\mathrm{HbA}_{1 \mathrm{c}}$ ) was performed using a normal likelihood, identity link, single parameter model (based on arm-level data), or a shared parameter model, which allows for a single coherent synthesis when outcome data is reported at both the arm level and trial level. For dichotomous outcomes, a binomial likelihood, logit link model was used for efficacy outcomes [e.g., proportion of patients achieving a $\mathrm{HbA}_{1 \mathrm{c}}$ level $\left.<7 \%(53 \mathrm{mmol} / \mathrm{mol})\right]$, while a binomial likelihood, cloglog link model was used for safety outcomes (e.g. ,incidence of overall hypoglycemia). All analyses were performed using a fixed effects (FE) model; the FE model provided a better model fit compared with the random effects (RE) model in terms of deviance information criterion and residual deviance.

The NMA models were implemented using WinBUGS software (MRC Biostatistics Unit, Cambridge, UK) [35] and employed a Bayesian framework with the inclusion of vague prior distributions. Three Markov Monte Carlo chains were used, starting from different initial values of selected unknown parameters. Convergence for all models were assessed by analyzing history and density plots, and Brooks-Gelman-Rubin diagnostic plots [36]. In addition, autocorrelation plots were assessed to detect the presence of autocorrelation in the chains. Following this, model convergence inferences were made from data obtained by sampling for a further 20,000 iterations.

For continuous outcomes, a mean treatment effect with an associated 95\% credible interval (CrI) is estimated and the treatment difference (95\% CrI) for semaglutide $0.5 \mathrm{mg} \mathrm{QW}$ vs comparator is presented. For dichotomous outcomes, an odds ratio (OR) with an associated 95\% CrI is calculated for semaglutide $0.5 \mathrm{mg}$ QW vs comparator. A difference between semaglutide $0.5 \mathrm{mg}$ QW and a comparator is assumed to only exist when the $95 \%$ CrI does not include the null value for treatment differences, or one for ORs.

Finally, this article does not contain any new studies with human or animal subjects performed by any of the authors.

\section{RESULTS}

\section{Identified Publications}

A total of 2387 unique citations of potential interest were identified in the electronic search and nine citations were identified in the supplementary searches. Data on two studies (NN9535-4091 and NN9535-4092) were provided by Novo Nordisk in the form of clinical trial summary reports (CSRs) ahead of publication. Both studies are now publicly available as full-text publications [31, 32]; henceforth, the NN9535-4091 trial is also referred to as "Kaku 2018" [32] and the NN9535-4092 trial is also referred to as "Seino 2018" [31]. Of these, 33 publications relating to 29 unique randomized controlled trials (RCTs) were considered to meet the inclusion criteria for the SR (the overall flow of studies across the SR and supplementary searches is shown in a PRISMA diagram in Fig. S1). In total, ten trials were considered to be the most relevant for the NMA. 
These ten trials were examined for time points for which data were available for at least one outcome of interest. Six trials reported on an outcome of interest between 23 and 30 weeks (approximately 6 months); however, an analysis at 30 weeks based on the duration of Seino 2018 [31] was not feasible, as no connected network between semaglutide and dulaglutide could be formed. The analysis at 56 weeks based on the duration of Kaku 2018 [32] was possible as three additional trials reported on an outcome of interest at 52 weeks (considered sufficiently close to 56 weeks to allow comparison) and formed a connected network with Kaku 2018 [32].

Within the four trials included in the analysis at 52-56 weeks, the intervention of interest (semaglutide $0.5 \mathrm{mg}$ QW) and two comparators of interest (dulaglutide QW and liraglutide QD) were assessed. Two trials included liraglutide $0.9 \mathrm{mg}$ QD, while one trial included dulaglutide $0.75 \mathrm{mg}$ QW; the dosages of both GLP-1 RAs represent the highest dose available in Japan $[23,37]$. A lower dose of liraglutide (liraglutide $0.6 \mathrm{mg}$ QD) was also reported in one trial. No trials assessing exenatide (BID or QW) or lixisenatide QD were eligible for inclusion in the NMA.

The study design and patient characteristics of the four trials included in the analysis at 52-56 weeks were generally similar and suitable for comparison within an evidence network (Table 1). All four studies were multicenter phase 3 trials conducted in Japan. The risk of bias (based on the NICE checklist) across the four trials was considered low (Fig. S2); however, Odawara 2016 [23] and Seino 2011 [38] were both double-blind trials, while Kaku 2016 and Kaku 2018 [22, 32] were both open-label trials. In line with the population of interest, all trials enrolled adult populations ( $\geq 20$ years) with T2DM who had not received any treatments $(n=2)$ or had received one OAD $(n=2)$. The mean age of trial populations ranged from 57.6 to 59.7 years, and $18.5-36.0 \%$ of patients were female. The mean weight of the patients was also similar across the trials and ranged from 65.8 to $71.6 \mathrm{~kg}$, while the mean BMI ranged from 24.9 to $26.5 \mathrm{~kg} / \mathrm{m}^{2}$. The characteristic with the greatest variability was the mean disease duration, which ranged from 6.6 to 10.3 years across the trials. However, the trials recruited patients of a similar level of disease severity as indicated by the baseline $\mathrm{HbA}_{1 \mathrm{c}}$ levels; all trials enrolled patients with a $\mathrm{HbA}_{1 \mathrm{c}}$ value of $>7 \%(53.0 \mathrm{mmol} / \mathrm{mol})$, which is suggestive of inadequate control as per the ADA guidelines, and the mean baseline $\mathrm{HbA}_{1 \mathrm{c}}$ ranged from $8.09 \%$ to $8.82 \%(64.9-72.9 \mathrm{mmol} / \mathrm{mol})$.

\section{Trial Data and Evidence Networks}

For the analysis at 52-56 weeks, outcomespecific evidence networks were possible for 7 of the 20 outcomes of interest assessed for feasibility. It should be noted that it was not possible to conduct NMAs on the majority of the safety outcomes included in the SR eligibility criteria (Table S1). This was due to a paucity of data, which precluded the ability to generate connected networks with semaglutide QW. All four trials reported data on $\mathrm{HbA}_{1 \mathrm{c}}$ [change from baseline and percentage achieving a $\mathrm{HbA}_{1 \mathrm{c}}$ level $<7.0 \%(53 \mathrm{mmol} / \mathrm{mol})]$ and FPG (change from baseline; Table S2) at 52-56 weeks and were used to construct an evidence network to compare these outcomes for semaglutide $0.5 \mathrm{mg}$ QW, dulaglutide $0.75 \mathrm{mg}$ QW, and liraglutide 0.6 and $0.9 \mathrm{mg}$ QD (Fig. 1); in this network, an additional OAD [metformin, SU, a-glucosidase inhibitor $(\alpha-\mathrm{GI}), \mathrm{TZD}$, dipeptidyl peptidase-4 (DPP-4) inhibitor, or a glinide] and placebo are essential secondary comparators. Although not a primary intervention of interest, semaglutide $1.0 \mathrm{mg}$ QW was included in the network as it was assessed alongside semaglutide $0.5 \mathrm{mg}$ QW in Kaku 2018 [32]; the results for semaglutide $0.5 \mathrm{mg}$ QW vs semaglutide $1.0 \mathrm{mg}$ QW are presented to aid interpretation. Three trials reported data for the change from baseline in SBP and weight, and the overall incidence of hypoglycemia at 52-56 weeks (Table S2). It should be noted that while the overall incidence of hypoglycemia was recorded in the NN95354091 trial, these data are not published in Kaku 2018 [32]; for transparency, these data have now been made available in Table S2. As Seino et al. [38] did not report any data for these outcomes, liraglutide $0.6 \mathrm{mg}$ QD is absent from 


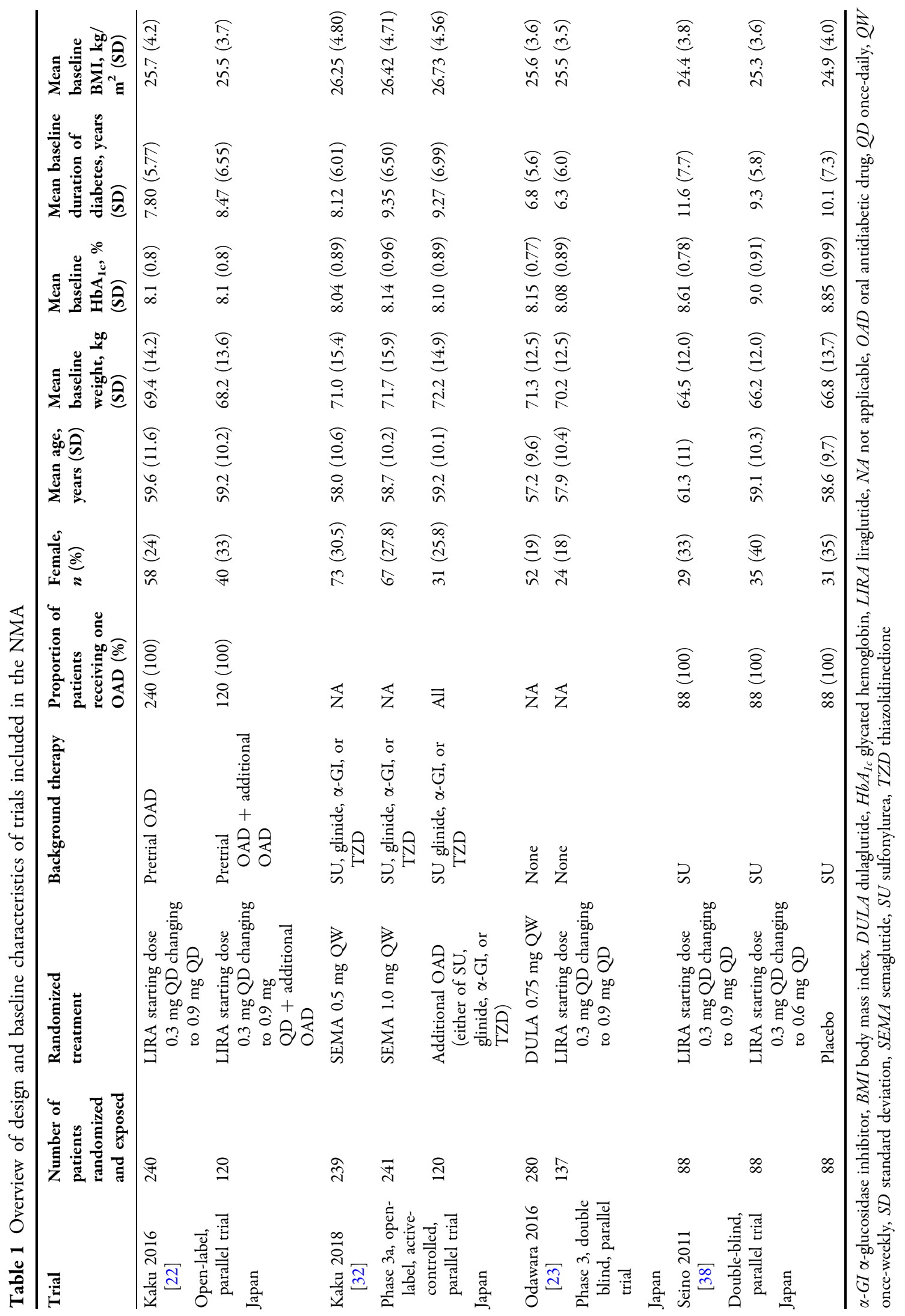



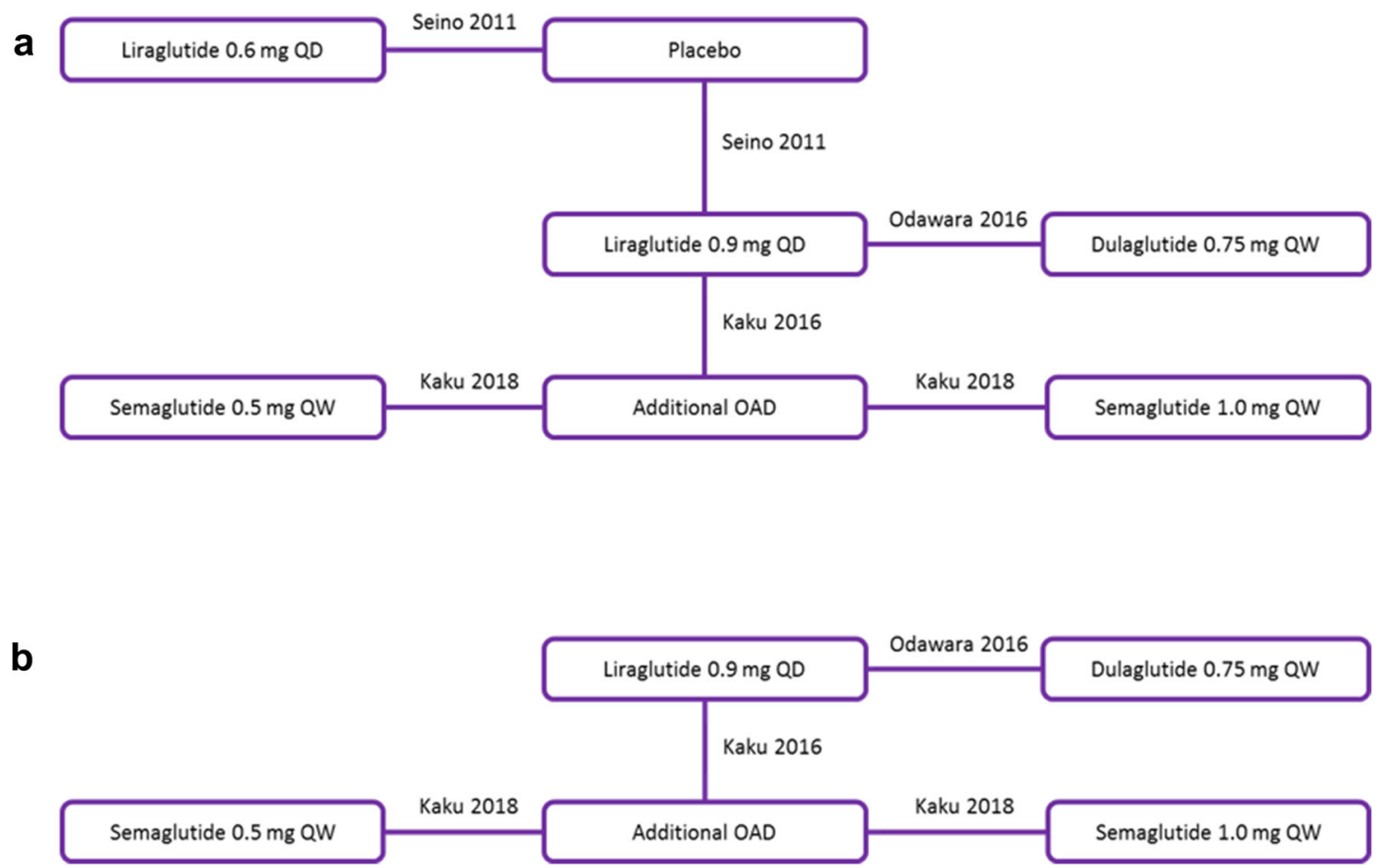

Fig. 1 Evidence networks for a $\mathrm{HbA}_{1 \mathrm{c}}$ (change from baseline and percentage achieving a $\mathrm{HbA}_{1 \mathrm{c}}$ level $<7.0 \%$ ( $53 \mathrm{mmol} / \mathrm{mol}$ ) and FPG (change from baseline), b SBP, weight (both change from baseline), and hypoglycemia (overall incidence). $\mathrm{HbA}_{1 \mathrm{c}}$ glycated hemoglobin, FPG fasting plasma glucose, OAD oral antidiabetic drug, QD once-daily, QW once-weekly, SBP systolic blood pressure

$-2.16 \mathrm{mmol} / \mathrm{L})$. The treatment differences compared with liraglutide 0.6 and $0.9 \mathrm{mg}$ QD were also significant in favor of semaglutide $0.5 \mathrm{mg}$ QW. An additional analysis of glycemic control showed that the likelihood of achieving a $\mathrm{HbA}_{1 \mathrm{c}}$ level $<7.0 \% \quad(53.0 \mathrm{mmol} / \mathrm{mol}) \quad$ was comparable between semaglutide $0.5 \mathrm{mg}$ QW and dulaglutide $0.75 \mathrm{mg}$ QW [OR 2.01 (95\% CrI $0.91,4.49)$, Table 2]; the likelihood of achieving this outcome was $78.4 \%$ and $64.3 \%$ for semaglutide $0.5 \mathrm{mg}$ QW and dulaglutide $0.75 \mathrm{mg}$ QW, respectively (Table S3). However, patients were found to be significantly more likely to achieve a $\mathrm{HbA}_{1 \mathrm{c}}$ level $<7.0 \%$ $(53.0 \mathrm{mmol} / \mathrm{mol})$ with semaglutide $0.5 \mathrm{mg}$ QW compared with liraglutide $0.6 \mathrm{mg}$ and $0.9 \mathrm{mg}$ QD (Table 2). Overall, semaglutide $1.0 \mathrm{mg}$ QW was associated with the greatest improvements in both $\mathrm{HbA}_{1 \mathrm{c}}$ and FPG.

The NMA results for the change from baseline in weight (Fig. 3) demonstrated that semaglutide $0.5 \mathrm{mg}$ QW is associated with a 


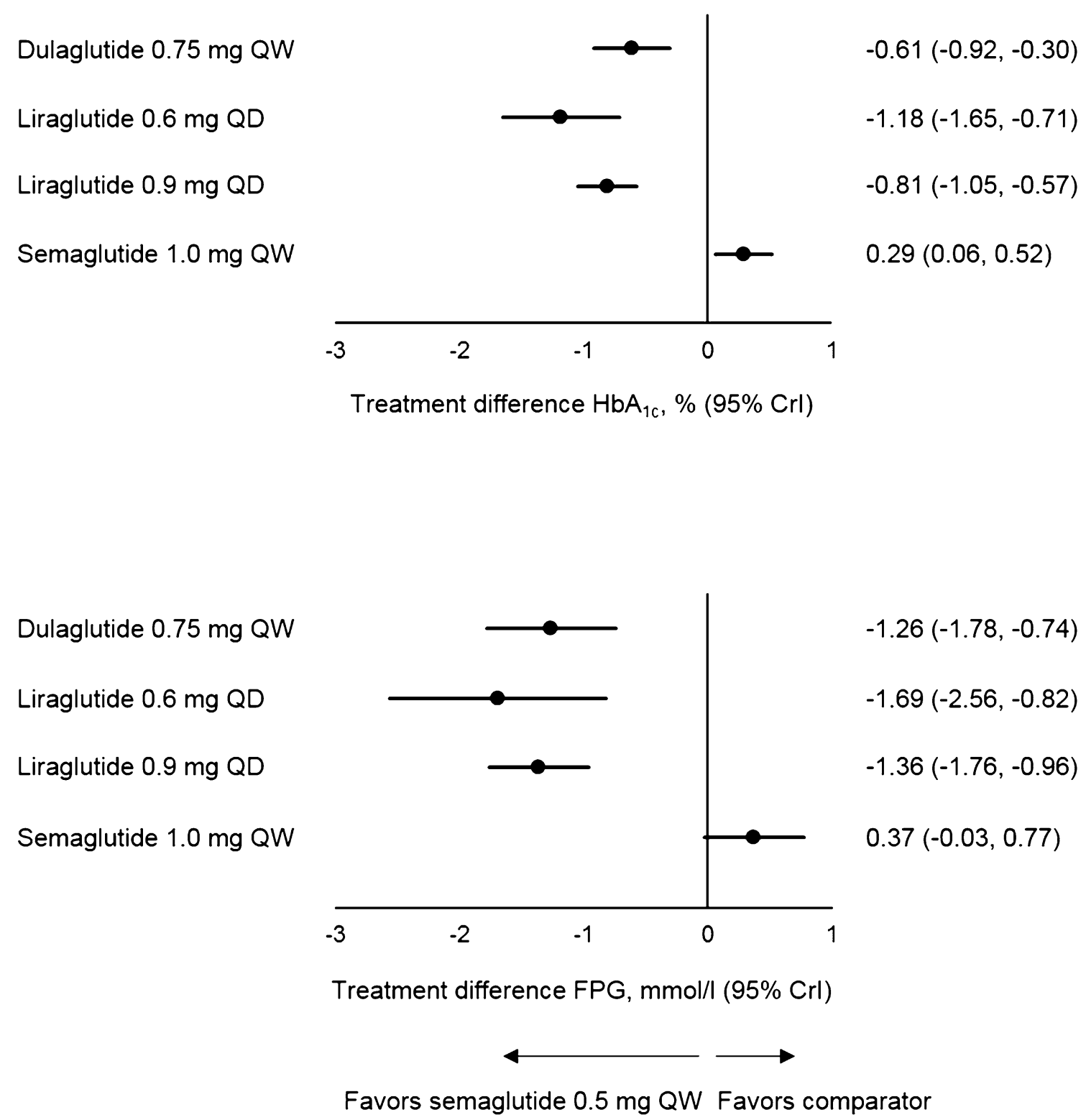

Fig. 2 Forest plots of the NMA results (semaglutide $0.5 \mathrm{mg} \mathrm{QW}$ vs comparator) for the change from baseline in $\mathrm{HbA}_{1 \mathrm{c}}$ and FPG. Treatment differences are considered significant when the $95 \% \mathrm{CrI}$ excludes the null value. $\mathrm{CrI}$

significant $1.45 \mathrm{~kg}$ (95\% CrI $-2.65,-0.25)$ reduction in weight compared with dulaglutide $0.75 \mathrm{mg}$ QW (absolute reduction -1.62 vs $-0.17 \mathrm{~kg}$; Table S3). The treatment difference compared with liraglutide $0.9 \mathrm{mg}$ QD was also significant in favor of semaglutide $0.5 \mathrm{mg}$ QW. The analysis of the change from baseline in SBP (Fig. 3) was associated with a higher level of uncertainty as shown by the wide 95\% CrIs. credible interval, FPG fasting plasma glucose, $\mathrm{HbA}_{1 \mathrm{c}}$ glycated hemoglobin, NMA network meta-analysis, QD once-daily, QW once-weekly

However, a significant reduction in SBP of $5.03 \mathrm{mmHg}(95 \%$ CrI $-9.29,-0.79)$ with semaglutide $0.5 \mathrm{mg}$ QW compared with dulaglutide $0.75 \mathrm{mg}$ QW was still observed (absolute difference from baseline -3.60 vs $1.45 \mathrm{mmHg}$; Table S3). Semaglutide $1.0 \mathrm{mg}$ QW demonstrated the greatest improvements in weight and SBP. 
Table 2 NMA results (semaglutide $0.5 \mathrm{mg}$ QW vs comparator) for percentage of patients achieving a $\mathrm{HbA}_{1 \mathrm{c}}$ level of $<7 \%(53 \mathrm{mmol} / \mathrm{mol})$ and the incidence of overall hypoglycemia

\begin{tabular}{lc}
\hline Comparator & $\begin{array}{c}\text { Odds ratio (95\% Cr } \\
\text { semaglutide 0.5 mg } \\
\text { comparator }\end{array}$ \\
\hline $\begin{array}{l}\text { Percentage of patients achieving a } \mathrm{HbA}_{1 \mathrm{c}} \\
(53 \mathrm{mmol} / \mathrm{mol})\end{array}$ & 2.01 $(0.91,4.49)$ \\
Dulaglutide & \\
$0.75 \mathrm{mg}$ QW & \\
Liraglutide & $\mathbf{1 0 . 6 4}(\mathbf{3 . 9 6}, \mathbf{2 9 . 3 6})$ \\
$0.6 \mathrm{mg}$ QD & \\
Liraglutide & $\mathbf{2 . 8 5}(\mathbf{1 . 4 5}, \mathbf{5 . 6 2})$ \\
$0.9 \mathrm{mg}$ QD & \\
Semaglutide & $\mathbf{0 . 4 9}(\mathbf{0 . 2 7}, \mathbf{0 . 8 5})$ \\
$1.0 \mathrm{mg}$ QW & \\
Incidence of overall hypoglycemia \\
Dulaglutide & $2.99(0.21,40.09)$ \\
$0.75 \mathrm{mg}$ QW & \\
Liraglutide & $3.11(0.31,30.35)$ \\
$0.9 \mathrm{mg}$ QD & \\
Semaglutide & $0.75(0.47,1.18)$ \\
$1.0 \mathrm{mg}$ QW & \\
\hline
\end{tabular}

Bold values indicate odds ratios where the associated 95\% CrI excludes 1

$\mathrm{CrI}$ credible interval, $H b A_{1 c}$ glycated hemoglobin, $N M A$ network meta-analysis, $Q D$ once-daily, $Q W$ once-weekly

Generally, the incidence of overall hypoglycemia was low across the three trials included in the NMA of this outcome (Table S2). Overall, the results of the NMA did not reveal any significant difference in the incidence of overall hypoglycemia between semaglutide $0.5 \mathrm{mg}$ QW and dulaglutide $0.75 \mathrm{mg}$ QW [OR 2.99 (95\% CrI 0.21, 40.09)] or liraglutide $0.9 \mathrm{mg}$ QD [OR 3.11 (95\% CrI 0.31, 30.35), Table 2]; the incidence was $5.2 \%, 1.8 \%$, and $1.7 \%$ for semaglutide $0.5 \mathrm{mg}$ QW, dulaglutide $0.75 \mathrm{mg}$ $\mathrm{QW}$, and liraglutide $0.9 \mathrm{mg} \mathrm{QD}$, respectively (Table S3). The risk of overall hypoglycemia was also similar between semaglutide $0.5 \mathrm{mg}$ QW and semaglutide $1.0 \mathrm{mg}$ QW.

\section{DISCUSSION}

The objective of this study was to assess the relative efficacy and safety of semaglutide $0.5 \mathrm{mg}$ QW vs GLP-1 RAs in Japanese patients, with a specific focus on the comparison between semaglutide $0.5 \mathrm{mg}$ QW and dulaglutide $0.75 \mathrm{mg}$ QW. Overall, semaglutide $0.5 \mathrm{mg}$ QW was associated with significant reductions from baseline in $\mathrm{HbA}_{1 \mathrm{c}}$, weight, SBP, and FPG, compared with dulaglutide $0.75 \mathrm{mg}$ QW. In addition, semaglutide $0.5 \mathrm{mg}$ QW achieved significant reductions from baseline in $\mathrm{HbA}_{1 \mathrm{c}}$ and FPG vs both liraglutide 0.6 and $0.9 \mathrm{mg} \mathrm{QW}$, and a significant reduction in weight vs liraglutide $0.9 \mathrm{mg}$ QW (liraglutide $0.6 \mathrm{mg}$ QD was not available for comparison). Furthermore, semaglutide $0.5 \mathrm{mg}$ QW was associated with significantly higher odds of achieving a $\mathrm{HbA}_{1 \mathrm{c}}$ level $<7 \% \quad(53.0 \mathrm{mmol} / \mathrm{mol})$ compared with liraglutide $0.6 \mathrm{mg}$ and $0.9 \mathrm{mg}$ QD.

To our knowledge, this is the first NMA comparing semaglutide QW with other GLP-1 RAs in a Japanese population. However, the results of this NMA can be compared with the recent head-to-head, multicenter (Asia, Europe, and the USA), clinical trial SUSTAIN 7, which assessed semaglutide QW and dulaglutide QW, both as an add-on to metformin [30]. The direction of effect for $\mathrm{HbA}_{1 \mathrm{c}}$ and weight demonstrated between semaglutide $0.5 \mathrm{mg}$ QW and dulaglutide $0.75 \mathrm{mg}$ QW in our analysis is broadly consistent with the data reported in SUSTAIN 7. In SUSTAIN 7 (which did not include any Japanese patients), semaglutide $0.5 \mathrm{mg}$ QW demonstrated a statistically significant reduction in $\mathrm{HbA}_{1 \mathrm{c}}(-1.5 \%$ vs $-1.1 \%)$ and weight $(-4.6 \mathrm{vs}-2.3 \mathrm{~kg})$ compared with dulaglutide $0.75 \mathrm{mg}$ at 40 weeks. This equates to a treatment difference of $-0.4 \%$ for $\mathrm{HbA}_{1 \mathrm{c}}$ and $-2.3 \mathrm{~kg}$ for weight (both in favor of semaglutide $0.5 \mathrm{mg}$ QW), which are similar to the treatment differences estimated in our NMA at $52-56$ weeks $[-0.61 \%(95 \% \mathrm{CrI}-0.92,-0.30)$ and $-1.45 \mathrm{~kg} \quad(95 \%$ CrI $-2.65,-0.25)$, respectively]. SUSTAIN 7 also demonstrated that more patients achieved a $\mathrm{HbA}_{1 \mathrm{c}}$ level $\leq 7 \%$ $(53.0 \mathrm{mmol} / \mathrm{mol})$ with semaglutide $0.5 \mathrm{mg} \mathrm{QW}$ compared with dulaglutide $0.75 \mathrm{mg}$ QW (69\% 


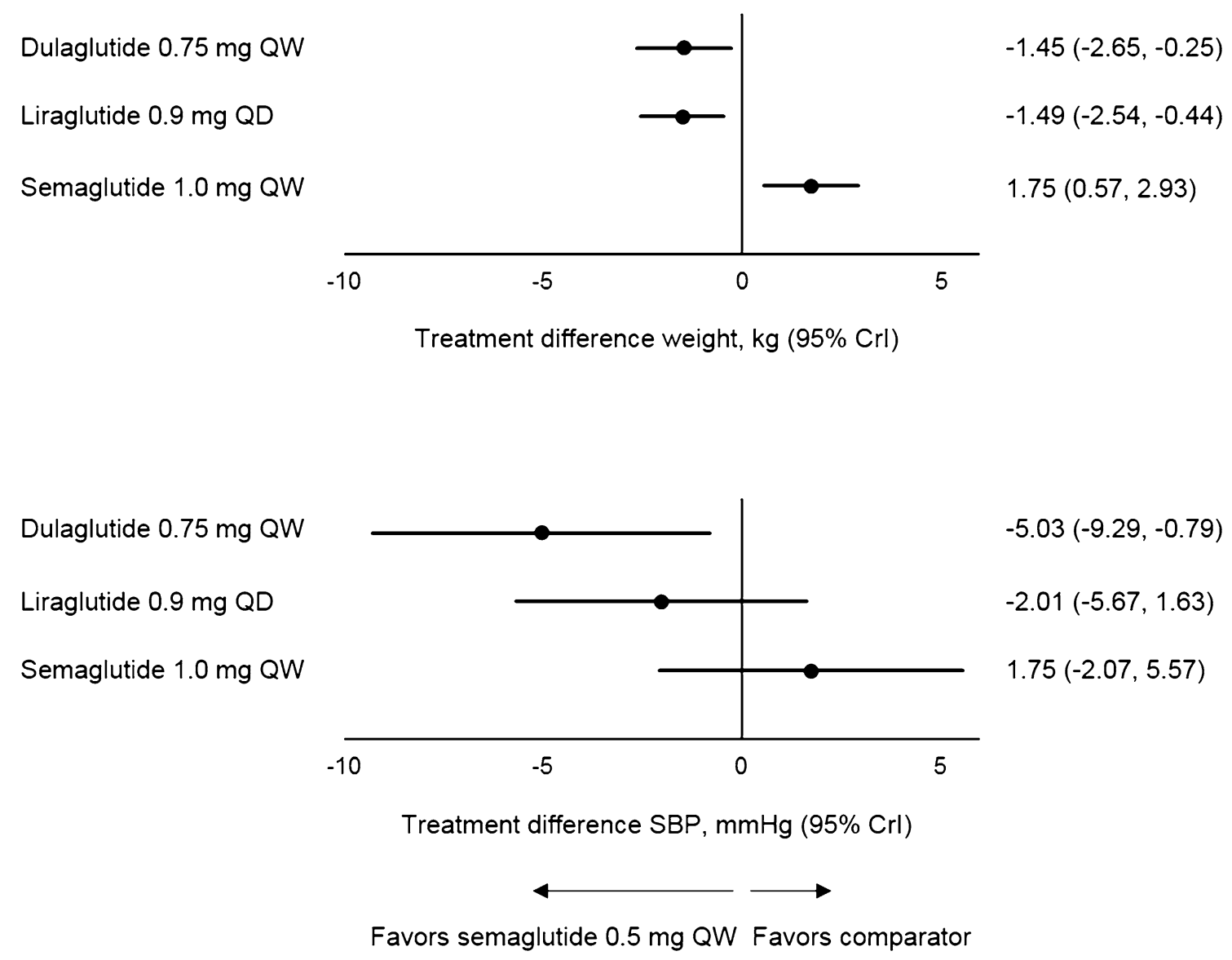

Fig. 3 Forest plots of the NMA results (semaglutide $0.5 \mathrm{mg}$ QW vs comparator) for the change from baseline in weight and SBP. Treatment differences are considered significant when the 95\% CrI excludes the null value. $\mathrm{CrI}$

vs $52 \%$ ). In our analysis, semaglutide $0.5 \mathrm{mg}$ QW was associated with an OR of 2.01 vs dulaglutide $0.75 \mathrm{mg}$ QW for the proportion of patients achieving a $\mathrm{HbA}_{1 \mathrm{c}}$ level $<7 \%$ $(53.0 \mathrm{mmol} / \mathrm{mol})$, thereby corroborating what was observed in SUSTAIN 7; however, as the 95\% CrI included 1, statistical significance could not be concluded.

Overall, our analysis provides a robust assessment of the efficacy of semaglutide QW across five outcomes compared with dulaglutide QW and liraglutide QD. In contrast, it was only possible to provide estimates for one safety outcome (incidence of overall hypoglycemia), which limits the ability to make any definitive conclusions from our study on the relative safety of semaglutide QW compared with other credible interval, FPG fasting plasma glucose, $\mathrm{HbA}_{1 \mathrm{c}}$ glycated hemoglobin, NMA network meta-analysis, QD once-daily, QW once-weekly, SBP systolic blood pressure

GLP-1 RAs. However, the two recent Japanese trials of semaglutide QW have demonstrated that its safety profile is comparable to other GLP-1 RAs [31, 32]. Our analysis of the incidence of overall hypoglycemia is in agreement with these findings, as no significant differences for semaglutide $0.5 \mathrm{mg}$ QW vs dulaglutide $0.75 \mathrm{mg}$ QW or liraglutide $0.9 \mathrm{mg}$ QD were detected. The NMAs were also subject to additional limitations. Although an SR and supplementary Japanese-specific searches were conducted to identify relevant trials, only four trials were available for the analysis at 52-56 weeks. Consequently, the direct comparisons within the evidence network were supported by data from only one trial each. In addition, while the overall risk of bias across the 
trials included in the analyses was low, the highest risk was associated with study blinding due to the presence of two open-label trials. The absence of double-blinding may be considered a limitation as this can potentially introduce performance bias into the NMA [39].

Analysis of a few secondary outcomes assessed may have also been limited by poor reporting or low event rates. The overall incidence of hypoglycemia was low across the trials, which may have contributed to greater uncertainty in the analysis. Hypoglycemic episodes are often underreported by patients, which may be due to reasons such as fear of being judged, losing their job or driving license, and unawareness of nocturnal events $[40,41]$. In addition, studies often report the number of patients with hypoglycemic events, rather than the actual frequency of events [41]. Furthermore, non-severe events are not always reported in trials. Patients may not consider such mild events as important enough to mention to their doctor [41, 42]. Greater uncertainty was also observed in the analysis of SBP, when compared to the analysis of $\mathrm{HbA}_{1 \mathrm{c}}, \mathrm{FPG}$, and weight. The measurement of SBP is known to be variable and values can differ for the same patient throughout the day. In addition, there are often patient, device-, and procedure-related inaccuracies in the way that blood pressure is monitored [43]. Together, these may have contributed to the uncertainty present in our analysis of SBP. Despite this, a significant difference in the reduction of SBP from baseline with semaglutide $0.5 \mathrm{mg}$ QW compared with dulaglutide $0.75 \mathrm{mg}$ QW was still observed.

\section{CONCLUSION}

Our analysis suggests that semaglutide $0.5 \mathrm{mg}$ QW provides greater efficacy compared with dulaglutide $0.75 \mathrm{mg}$ QW in the treatment of Japanese patients with T2DM. Statistically significant improvements for semaglutide $0.5 \mathrm{mg}$ QW vs dulaglutide $0.75 \mathrm{mg}$ QW were found for $\mathrm{HbA}_{1 \mathrm{c}}$, weight, SBP, and FPG. In the absence of head-to-head trials between semaglutide QW and other GLP-1 RAs in a Japanese population, this NMA provides an estimate of the relative efficacy of semaglutide QW. Following the recent introduction of HTA in Japan, and the increasing amount of treatment options available for T2DM, these data provide valuable evidence for decision-making and cost-effectiveness analyses.

\section{ACKNOWLEDGEMENTS}

Funding. This study, medical writing, and article processing charges were funded by Novo Nordisk Pharma Ltd.

Editorial Assistance. Editorial assistance in the preparation of this manuscript was provided by Alan Weids of DRG Abacus. Support for this assistance was funded by Novo Nordisk Pharma Ltd.

Authorship. All named authors meet the International Committee of Medical Journal Editors (ICMJE) criteria for authorship for this manuscript, take responsibility for the integrity of the work as a whole, and have given final approval for the version to be published. All authors had full access to all of the data in this study and take complete responsibility for the integrity of the data and accuracy of the data analysis.

Disclosures. Jakob Langer is an employee of Novo Nordisk Pharma Ltd. and shareholder of Novo Nordisk A/S. Rie Nakanishi is an employee of Novo Nordisk Pharma Ltd. Neil Webb is an employee of DRG Abacus. Michal Witkowski is an employee of DRG Abacus. Michelle Orme received funding from Novo Nordisk Pharma Ltd. to conduct the analysis.

Compliance with Ethics Guidelines. This article does not contain any new studies with human or animal subjects performed by any of the authors.

Data Availability. The datasets generated and/or analyzed during the current study are available from the corresponding author on reasonable request. 
Open Access. This article is distributed under the terms of the Creative Commons Attribution-NonCommercial 4.0 International License (http://creativecommons.org/licenses/ by-nc/4.0/), which permits any noncommercial use, distribution, and reproduction in any medium, provided you give appropriate credit to the original author(s) and the source, provide a link to the Creative Commons license, and indicate if changes were made.

\section{REFERENCES}

1. Saini V. Molecular mechanisms of insulin resistance in type 2 diabetes mellitus. World J Diabetes. 2010;1(3):68-75.

2. Stratton IM, Adler AI, Neil HA, et al. Association of glycaemia with macrovascular and microvascular complications of type 2 diabetes (UKPDS 35): prospective observational study. BMJ. 2000;321(7258):405-12.

3. Ogurtsova K, da Rocha Fernandes JD, Huang Y, et al. IDF Diabetes Atlas: global estimates for the prevalence of diabetes for 2015 and 2040. Diabetes Res Clin Pract. 2017;128:40-50.

4. Ministry of Health, Labour and Welfare. Results of Heisei 28 "National Health and Nutrition Survey" [in Japanese]. 2017. http://www.mhlw.go.jp/stf/ houdou/0000177189.html. Accessed Dec 2017.

5. Mukai N, Doi Y, Ninomiya T, et al. Trends in the prevalence of type 2 diabetes and prediabetes in community-dwelling Japanese subjects: the Hisayama study. J Diabetes Investig. 2014;5(2):162-9.

6. Inzucchi SE, Bergenstal RM, Buse JB, et al. Management of hyperglycaemia in type 2 diabetes, 2015: a patient-centred approach. Update to a position statement of the American Diabetes Association and the European Association for the Study of Diabetes. Diabetologia. 2015;58(3):429-42.

7. Tanaka S, Tanaka S, Iimuro S, et al. Predicting macro- and microvascular complications in type 2 diabetes: the Japan Diabetes Complications Study/ the Japanese Elderly Diabetes Intervention Trial risk engine. Diabetes Care. 2013;36(5):1193-9.

8. Araki E, Haneda M, Kasuga M, et al. New glycemic targets for patients with diabetes from the Japan Diabetes Society. J Diabetes Investig. 2017;8(1):123-5
9. Yokoyama H, Oishi $\mathrm{M}$, Takamura $\mathrm{H}$, et al. Largescale survey of rates of achieving targets for blood glucose, blood pressure, and lipids and prevalence of complications in type 2 diabetes (JDDM 40). BMJ Open Diabetes Res Care. 2016;4(1):e000294.

10. Russell-Jones D, Khan R. Insulin-associated weight gain in diabetes-causes, effects and coping strategies. Diabetes Obes Metab. 2007;9(6):799-812.

11. Carver C. Insulin treatment and the problem of weight gain in type 2 diabetes. Diabetes Educ. 2006;32(6):910-7.

12. Prasad-Reddy L, Isaacs D. A clinical review of GLP-1 receptor agonists: efficacy and safety in diabetes and beyond. Drugs Context. 2015;4:212283.

13. Baggio LL, Drucker DJ. Biology of incretins: GLP-1 and GIP. Gastroenterology. 2007;132(6):2131-57.

14. Kalra S, Baruah MP, Sahay RK, Unnikrishnan AG, Uppal S, Adetunji O. Glucagon-like peptide-1 receptor agonists in the treatment of type 2 diabetes: past, present, and future. Indian J Endocrinol Metab. 2016;20(2):254-67.

15. Pozzilli P, Norwood P, Jodar E, et al. Improved glycemic control and weight loss with once-weekly dulaglutide vs placebo, both added to titrated daily insulin glargine, in type 2 diabetes patients (AWARD-9). In: American Diabetes Association's 76th scientific sessions, New Orleans, LA, 12 June 2016.

16. Pozzilli P, Norwood P, Jodar E, et al. Placebo-controlled, randomized trial of the addition of onceweekly glucagon-like peptide-1 receptor agonist dulaglutide to titrated daily insulin glargine in patients with type 2 diabetes (AWARD-9). Diabetes Obes Metab. 2017;19(7):1024-31.

17. Russell-Jones D, Vaag A, Schmitz O, et al. Liraglutide vs insulin glargine and placebo in combination with metformin and sulfonylurea therapy in type 2 diabetes mellitus (LEAD-5 met $+\mathrm{SU}$ ): a randomised controlled trial. Diabetologia. 2009;52(10):2046-55.

18. Mundil D, Cameron-Vendrig A, Husain M. GLP-1 receptor agonists: a clinical perspective on cardiovascular effects. Diabetes Vasc Dis Res. 2012;9(2):95-108.

19. Araki E, Inagaki N, Tanizawa $Y$, Oura T, Takeuchi M, Imaoka T. Efficacy and safety of once-weekly dulaglutide in combination with sulphonylurea and/or biguanide compared with once-daily insulin glargine in Japanese patients with type 2 diabetes: a randomized, open-label, phase III, non-inferiority study. Diabetes Obes Metab. 2015;17(10):994-1002. 
20. Inagaki N, Atsumi Y, Oura T, Saito H, Imaoka T. Efficacy and safety profile of exenatide once weekly compared with insulin once daily in Japanese patients with type 2 diabetes treated with oral antidiabetes drug(s): results from a 26-week, randomized, open-label, parallel-group, multicenter, noninferiority study. Clin Ther. 2012;34(9):1892.e1-1908.e1.

21. Inagaki N, Ueki K, Yamamura A, Saito H, Imaoka T. Long-term safety and efficacy of exenatide twice daily in Japanese patients with suboptimally controlled type 2 diabetes. J Diabetes Investig. $2011 ; 2(6): 448-56$.

22. Kaku K, Kiyosue A, Ono Y, et al. Liraglutide is effective and well tolerated in combination with an oral antidiabetic drug in Japanese patients with type 2 diabetes: a randomized, 52-week, open-label, parallel-group trial. J Diabetes Investig. 2016;7(1):76-84.

23. Odawara $\mathrm{M}$, Miyagawa J, Iwamoto $\mathrm{N}$, Takita $\mathrm{Y}$, Imaoka T, Takamura T. Once-weekly glucagon-like peptide-1 receptor agonist dulaglutide significantly decreases glycated haemoglobin compared with once-daily liraglutide in Japanese patients with type 2 diabetes: 52 weeks of treatment in a randomized phase III study. Diabetes Obes Metab. 2016;18(3):249-57.

24. Kim YG, Hahn S, Oh TJ, Park KS, Cho YM. Differences in the HbA1c-lowering efficacy of glucagonlike peptide- 1 analogues between Asians and nonAsians: a systematic review and meta-analysis. Diabetes Obes Metab. 2014;16(10):900-9.

25. Terauchi $Y$, Satoi $Y$, Takeuchi M, Imaoka $T$. Monotherapy with the once weekly GLP-1 receptor agonist dulaglutide for 12 weeks in Japanese patients with type 2 diabetes: dose-dependent effects on glycaemic control in a randomised, double-blind, placebo-controlled study. Endocr J. 2014;61(10):949-59.

26. Seino Y, Takami A, Boka G, Niemoeller E, Raccah D. Pharmacodynamics of the glucagon-like peptide-1 receptor agonist lixisenatide in Japanese and Caucasian patients with type 2 diabetes mellitus poorly controlled on sulphonylureas with/without metformin. Diabetes Obes Metab. 2014;16(8):739-47.

27. Yabe D, Seino Y, Fukushima M, Seino S. Beta cell dysfunction versus insulin resistance in the pathogenesis of type 2 diabetes in East Asians. Curr Diab Rep. 2015;15(6):602.

28. Seino Y, Kuwata H, Yabe D. Incretin-based drugs for type 2 diabetes: focus on East Asian perspectives. J Diabetes Investig. 2016;7(Suppl 1):102-9.
29. Hramiak I, Ahmann A, Capethorn M, et al. Efficacy and safety of once-weekly semaglutide vs. exenatide ER after 56 weeks in subjects with type 2 diabetes (SUSTAIN 3). Can J Diabetes. 2016;40(5):S41.

30. Pratley R, Aroda V, Lingvay I, et al. Semaglutide versus dulaglutide once weekly in patients with type 2 diabetes (SUSTAIN 7): a randomised, openlabel, phase $3 \mathrm{~b}$ trial. Lancet Diabetes Endocrinol. 2018. https://doi.org/10.1016/S2213-8587(18)300 $24-X$.

31. Seino $Y$, Terauchi $Y$, Osonoi $T$, et al. Safety and efficacy of semaglutide once weekly vs sitagliptin once daily, both as monotherapy in Japanese people with type 2 diabetes. Diabetes Obes Metab. 2018;20(2):378-388.

32. Kaku K, Yamada Y, et al. Safety and efficacy of onceweekly semaglutide versus additional oral antidiabetic drugs, in Japanese people with inadequately controlled type 2 diabetes: a randomized trial. Diabetes Obes Metab. 2018. https://doi.org/10. 1111/dom.13218.

33. Moher D, Liberati A, Tetzlaff J, Altman DG, PRISMA Group. Preferred reporting items for systematic reviews and meta-analyses: the PRISMA statement. BMJ. 2009;339:b2535.

34. National Institute for Health and Care Excellence. Single technology appraisal: user guide for company evidence submission template. 2015. https:// www.nice.org.uk/process/pmg24/resources/singletechnology-appraisal-user-guide-for-company-evid ence-submission-template-pdf-72286715419333. Accessed Mar 2018.

35. Lunn D, Jackson C, Best N, Thomas A, Spiegelhalter D. The BUGS book a practical introduction to Bayesian analysis. Boca Raton: CRC; 2013.

36. Welton NJ, Sutton AJ, Cooper NJ, Abrams KR, Ades AE. Evidence synthesis for decision making in healthcare. 1st ed. New York: Wiley; 2012.

37. Suzuki S, Oura T, Takeuchi M, Boye KS. Evaluation of the impact of once weekly dulaglutide on patient-reported outcomes in Japanese patients with type 2 diabetes: comparisons with liraglutide, insulin glargine, and placebo in two randomized studies. Health Qual Life Outcomes. 2017;15(1):123.

38. Seino Y, Rasmussen MF, Nishida T, Kaku K. Glucagon-like peptide- 1 analog liraglutide in combination with sulfonylurea safely improves blood glucose measures vs sulfonylurea monotherapy in Japanese patients with type 2 diabetes: results of a 52-week, randomized, multicenter trial. J Diabetes Investig. 2011;2(4):280-6. 
39. Turner RM, Spiegelhalter DJ, Smith GC, Thompson SG. Bias modelling in evidence synthesis. J R Stat Soc Ser A Stat Soc. 2009;172(1):21-47.

40. Graveling AJ, Frier BM. Hypoglycaemia: an overview. Prim Care Diabetes. 2009;3(3):131-9.

41. Elliott L, Fidler C, Ditchfield A, Stissing T. Hypoglycemia event rates: a comparison between realworld data and randomized controlled trial populations in insulin-treated diabetes. Diabetes Ther. 2016;7(1):45-60.
42. Ostenson CG, Geelhoed-Duijvestijn P, Lahtela J, Weitgasser R, Markert Jensen M, Pedersen-Bjergaard U. Self-reported non-severe hypoglycaemic events in Europe. Diabet Med. 2014;31(1):92-101.

43. Kallioinen N, Hill A, Horswill MS, Ward HE, Watson MO. Sources of inaccuracy in the measurement of adult patients' resting blood pressure in clinical settings: a systematic review. J Hypertens. 2017;35(3):421-41. 